Chapter 8

\title{
Insecticide Resistence of Bumblebee Species
}

\author{
Marie Zarevúcka \\ Additional information is available at the end of the chapter \\ http://dx.doi.org/10.5772/56181
}

\section{Introduction}

Bumblebees are important pollinators of many crops and wild flowers and there are both conservation and economic reasons for taking action to assess the impact of pesticides on bumblebees. Pesticide risk assessments for honeybees are based on hazard ratios which rely on application rates and toxicity data and are unlikely to be appropriate for bumblebees. Bumblebees are active at different times and on different crop species and are, therefore, likely to have different exposure profiles. Unlike honeybees, deaths of bumblebees due to pesticides are unlikely to be reported, since the bees are not kept domestically and will die in small numbers. During the last decades side-effects of insecticides on bees have gained great attention due to their value as pollinators. In Europe insecticides are tested following the EPPO (European and Mediterranean Plant Protection Organization) guidelines to exclude any harm to honeybees Apis mellifera. Unfortunately there has been a decline in the abundance of bumblebees (Bombus sp., Apidae) in many countries, and it is possible that this is due in part to the use of certain pesticides.

Mechanisms of insecticide resistance found in insects may include three general categories. Modified behavioral mechanisms can let the insects avoid the exposure to toxic compounds. The second category is physiological mechanisms such as altered penetration, rapid excretion, lower rate transportation, or increase storage of insecticides by insects. The third category relies on biochemical mechanisms including the insensivity of target sites to insecticides and enhanced detoxification rate by several detoxifying mechanisms [1]. The representative detoxifying enzymes are general esterases and monooxygenases that catalyse the toxic compounds to be more water-soluble forms and the secondary metabolism is followed by conjugation reactions including those catalysed by glutathion S-transferases.

Insecticide resistance is the development by some insects in a population of an ability to survive doses of a toxicant which would prove lethal to the majority of individuals in a normal 
population of the same species [2]. Insecticide resistance has serious consequences, such as outright control failure, increased application rates, decreased yields, environmental contamination and wildlife and natural enemy destruction [3].

\section{Effect of insecticides}

Insecticides affect insect behavior, such as reducing movements and affecting feeding levels. To date risks assessment studies conducting the side-effects of conventional insecticides are mostly limited to acute toxicity studies. Overall, when considering conventional insecticides it is remarkable that several litle of all compounds included $(n=63)$ was considered as non-toxic (Figure 1)

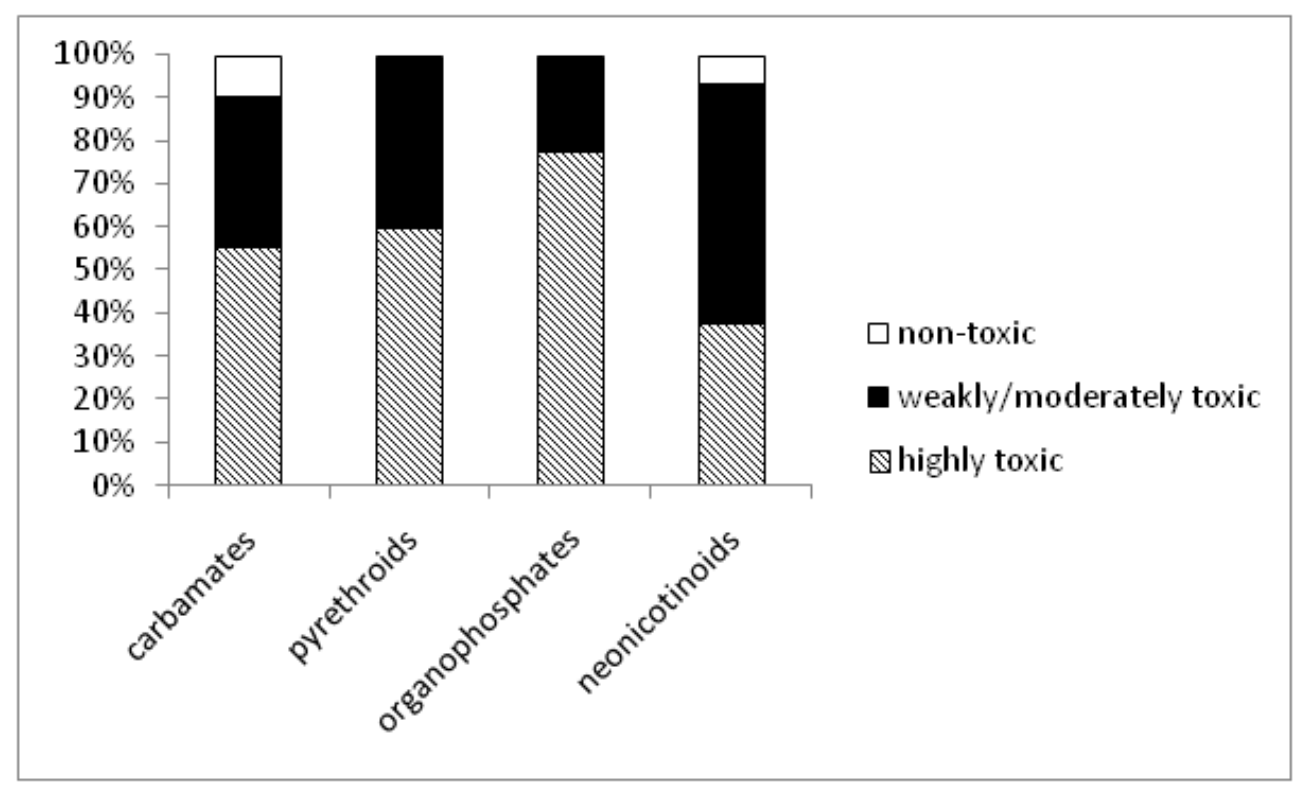

Figure 1. Overview of the toxicity of chemical insecticides towards bumblebees (Bombus terrestris). For each insecticide group the bars represent the percentage of compounds which are non-toxic, weakly/moderately toxic and toxic. The numbers of compounds considered per group are $n=11$ for carbamates, $n=14$ for pyrethroids, $n=32$ for organophosphates, $\mathrm{n}=6$ for neonicotinoids [4]. 
Cases where insecticides have altered insect behavior have only been reported for imidacloprid (systemic neonicotinoid and insect neurotoxin). Perhaps imidacloprid has been the most investigated insecticide because for a long time it was considered to be relatively safe to nontarget organisms, and thus was desired as a companion to biological control systems in integrated pest management systems. They may not only affect pest insects but also non-target organisms such as pollinators. Three different key aspects determining the risks of neonicotinoid concentrations for bee populations: (1) the environmental neonicotinoid residue levels in plants, bees and bee products in relation to pesticide application, (2) the reported side-effects with special attention for sublethal effects, and (3) the usefulness for the evaluation of neonicotinoids of an already existing risk assessment scheme for systemic compounds [5].

Imidacloprid probably migrate into nectar and pollen, then modify flower attractiveness, homing behavior, and colony development [6]. It was concluded that applying imidacloprid at the registered dose did not significantly affect the foraging and homing behavior of $B$. terestris and its colony development.The toxicity of imidacloprid to bees differs from most insecticides in that it is more toxic orally than by contact.

The imidacloprid was exposed adult worker bumble bees, Bombus terrestris, and honey bees, Apis mellifera L., to dietary in feeder syrup. Honey bees showed no response to dietary imidacloprid on any variable that was measured (feeding, locomotion and longevity) [7]. In contrast, bumble bees progressively developed over time a dose-dependent reduction in feeding rate but neither their locomotory activity nor longevity varied with diet. The honey bees are better pre-adapted than bumble bees to feed on nectars containing synthetic alkaloids, such as imidacloprid, by virtue of their ancestral adaptation to tropical nectars in which natural alkaloids are prevalent.

Neonicotinoid insecticides have been implicated in these declines because they occur at trace levels in the nectar and pollen of crop plants [8]. Colonies of the bumble bee Bombus terrestris in the laboratory were exposed to field-realistic levels of the neonicotinoid imidacloprid, then allowed them to develop naturally under field conditions. Treated colonies had a significantly reduced growth rate and suffered an $85 \%$ reduction in production of new queens compared with control colonies. The residual effects of insecticide treatments on colony vitality and behavior of the bumble bees Bombus impatiens foraging on turf containing white clover, Trifolium repens imidacloprid, was tested. The insecticide was applied as granules, followed by irrigation, or sprayed as a wettable powder, with or without irrigation [9] imidacloprid granules, and imidacloprid sprays applied with posttreatment irrigation, had no effect on colony vitality or workers' behavior, suggesting that such treatments pose little systemic or residual hazard to bumble bees. The direct contact toxicity of five technical grade insecticidesimidacloprid, clothianidin, deltamethrin, spinosad, and novaluron-was investigated on bees that may forage in canola: common eastern bumble bees (Bombus impatiens), alfalfa leafcutting bees (Megachile rotundata), and Osmia lignaria [10] Clothianidin and lesser extent imidacloprid were highly toxic to all three species, deltamethrin and spinosad were intermediate in toxicity, and novaluron was nontoxic. Bumble bees were generally more tolerant to the direct contact applications in comparison to leafcutting bees (Table 1). 
The insecticide Teppeki can be selective about bumble and have a good compatibility with the activity of the apiaries [11]. This insecticide has the active ingredient flonicamid belonging to a new chemical class, called pyridinecarboxamides: the product has systemic effect and is known as having a long lasting efficacy against all important aphid species The flonicamid has a minor effect of interference with the activity of pollination by B. terrestris, compared to the standard used. Treatment with Teppeki has not given any acute effect on B. terrestris, nor any effect of interference in respect of its pollination activity.

\begin{tabular}{|c|c|c|}
\hline insecticide & LC50 ( $\%$ solution $\left.\times 10^{-3}\right)$ & Pesticide mode of activity \\
\hline Clothianidin & 0.39 & $\begin{array}{l}\text { act on the central nervous system of insects as an agonist of } \\
\text { acetylcholine }\end{array}$ \\
\hline Imidacloprid & 3.22 & central nervous system, acetylcholine agonist \\
\hline Deltamethrin & 6.90 & due to irreversible damage to the nervous systém of insect \\
\hline Spinosad & $8.95^{\mathrm{a}}$ & $\begin{array}{l}\text { binding sites on nicotinic acetylcholine receptors ( } n A C h R s \text { ) of the } \\
\text { insect nervous system, binding leads to disruption of } \\
\text { acetylcholine neurotransmission }\end{array}$ \\
\hline Novaluron & $>100^{a}$ & $\begin{array}{l}\text { insect growth regulator that disrupts cuticle formation and } \\
\text { prevents molting }\end{array}$ \\
\hline
\end{tabular}

${ }^{a}$ No mortality at the highest concentration tested ( $0.1 \%$ solution).

Table 1. Direct contact toxicity of technical grade insecticides after $48 \mathrm{~h}$ to bumble bees [10]

As has been already shown pesticide risk assessments are routinely carried out for honeybees, but the results of these are probably not directly applicable to bumblebees [12]. Pyrethroids are commonly applied to flowering oilseed rape in the early morning or evening, when bumblebees are often active. Laboratory and field-based bioassays appropriate to bumblebees have been developed in response to the growing use of bumblebees for the pollination of greenhouse crops, but these are not widely used and few toxicological data are available [12]. Almost all tests conducted so far have been on B. terrestris, and suggest that toxicity is similar to that found in honeybees. Tests with dimethoate and carbofuran suggest that these chemicals are selectively transported into the nectar where they can reach high concentrations [13]. When colonies are large it is likely that they can tolerate the loss of some of their workers. However, in the spring when queens are foraging, and subsequently when nests are small and contain just a few workers, mortality may have a more significant effect [14].

Despite risk assessments, widespread poisoning of honeybees has been reported [15]. Such effects are obvious in domestic hives where dead bees are ejected and form piles by the nest. It seems probable that pesticides would have similar effects on bumblebees but they are unlikely to be noticed in most situations. In Canada, the use of the insecticide fenitrothion in 
forests led to a decline in yield of nearby Vaccinium crops due to a reduction in abundance of bumblebee pollinators [16]. In the UK, bumblebee deaths have been reported following applications of dimethoate or alphacypermethrin to flowering oilseed rape, and of $\lambda$-cyhalothrin to field beans $[12,14]$.

A growing appreciation of the damaging effects of broad-spectrum pesticides has led to the development of a new generation of more target-specific compounds. EU, US and Canadian law now demand that oral and acute toxicity tests are carried out on honeybees prior to the registration of any new pesticide [17]. However, there is no obligation to study sub-lethal effects on any bees, or to look at specific effects on bumblebees. Some of these substances cause no mortality in bumblebees if used appropriately $[18,19])$, but there is evidence that supplementary trials for non-lethal effects are necessary.

The spinosad is a commonly used insect neurotoxin which, based on studies of honeybees, has been deemed harmless to bees. However, it has recently been shown that bumblebee larvae fed with pollen containing this pesticide give rise to workers with reduced foraging efficiency [20]. Mommaerts et al. [21] screened eight chitin synthesis inhibitors currently registered as pesticides and found that although no lethal effect could be found on adults, the use of these pesticides has strong effects on colony growth and the development of larvae. Diflubenzuron and teflubenzuron were found to be the most harmful to bumblebees, greatly reducing reproductive output at concentrations far below the recommended field concentrations.

The effects of a naturally derived biopesticide, spinosad, was tested on bumble bee (Bombus impatiens) colony health, including adult mortality, brood development, weights of emerging bees and foraging efficiency of adults that underwent larval development during exposure to spinosad [20]. The colonies from an early stage was monitored, over a 10-week period, and fed spinosad to colonies in pollen at different concentrations during weeks The minimal negative effects to bumble bee colonies was detected at small concentrations of spinosad.

The toxicity of this Pyridalyl an insecticide of a novel chemical class (unclassified insecticides) to the pollinating insect Bombus terrestris, was evaluated using the body-dipping method or direct spray method [22]. No acute toxicity of this product was observed on these non-target insects. Moreover, the influence of pyridalyl to the nest of Bombus terrestris was evaluated using the direct spray to the inside of the nest. No apparent influence of this compound was observed by 21 days after treatment.

Gradish et al., determined the lethal and sub-lethal effects of four insecticides (imidacloprid, abamectin, metaflumizone and chlorantraniliprole) tested for use in greenhouse vegetable production to B. impatiens [23]. Imidacloprid, abamectin, and metaflumizone were harmful to worker bees following direct contact, while chlorantraniliprole was harmless. Worker bees fed imidacloprid-contaminated pollen had shortened life and were unable to produce brood. Worker bees consumed less pollen contaminated with abamectin. The new reduced risk insecticides metaflumizone and chlorantraniliprole are safe for greenhouse use in the presence of bumble bees.

The potential side effects of the novel insecticide spinetoram in comparison with spinosad on the bumblebee Bombus terrestris was determined by Besard et al. [24]. The potential lethal 
effects together with the ecologically relevant sublethal effects on aspects of bumblebee reproduction and foraging behaviour were evaluated. Overall, the results indicate that the use of spinetoram is safer for bumblebees by direct contact and oral exposure than the use of spinosad, and therefore it can be applied safely in combination with $B$. terrestris. The data provide strong evidence that neither spinosyn has a negative effect on the foraging behaviour of these beneficial insects.

Upon topical treatment, nitro-containing neonicotinoids (imidacloprid, clothianidin, thiamethoxam, nitenpyram and dinotefuran) were more toxic than the cyano-group containing ones (acetamiprid and thiacloprid) [25,26]. A similar high toxicity of imidacloprid and thiamethoxam was also found for the bumble bee Bombus terrestris [27]. The lower toxicity of the cyanogroup neonicotinoids can be attributed to their fast biotransformation [28-30] and the existence of different $n A C h R$ subtypes [31,32], however, found that bumble bees (Bombus impatiens) were more tolerant to clothianidin and imidacloprid than Osmia lignaria and M. rotundata.

\section{The effect of insecticides on insect immunity}

Individual immune defences in the bee parallel the innate immune systems of vertebrates [33], Figure 2. Insect immunity is basically composed of three parts: (1) the cuticle, which presents physical and chemical barriers to the outside world of microbes, (2) humoral responses, and (3) cellular responses. The primary defences are the cuticle, the spiracles and trachea and the alimentary canal including the intestinal epithelium and peritrophic membrane [34-36] If these are breached cellular immune defences include the cellular response represented by phagocytosis by haemocytes and melanisation.Insecticides affect the insect humoral and cellular immune responses. In the initial humoral response, pattern recognition proteins identify invading microbes and initiate the synthesis of various ofantimicrobial proteins [37], (Figure 2). Phagocytosis is typically accompanied by melanin production and melanization of nodules and capsules (Figure 1). Melanin production can occur morerapidly than the production of antimicrobial peptides, can lead to the formation of reactive oxidative species that can contribute to killing pathogens and are regulated through the phenoloxidase cascade [38], (Figure 2). The humoral and cellular responses are interdependent defensive forces involving detoxificationmechanisms that are also utilized by insects to prevent damage from environmental toxins. The humoral response is represented by secretion of antimicrobial peptides (AMPs, inducible antibioticpeptides such as apidaecins) $[39,40]$ from within the fat body due to the activation of one or several intracellular signalling pathways (Toll, Imd and Jak-Stat) which degrade pathogens as well as the action of reactive oxygen and nitrogen species (Figure 2).

To date risks assessment studies conducting the side-effects of conventional insecticides are mostly limited to acute toxicity studies. A summary of the effects of the insecticides including the organochlorides, organophosphates, carbamates, pyrethroids, organophosphates and neonicotinoids on insect is given in Table 2 . 


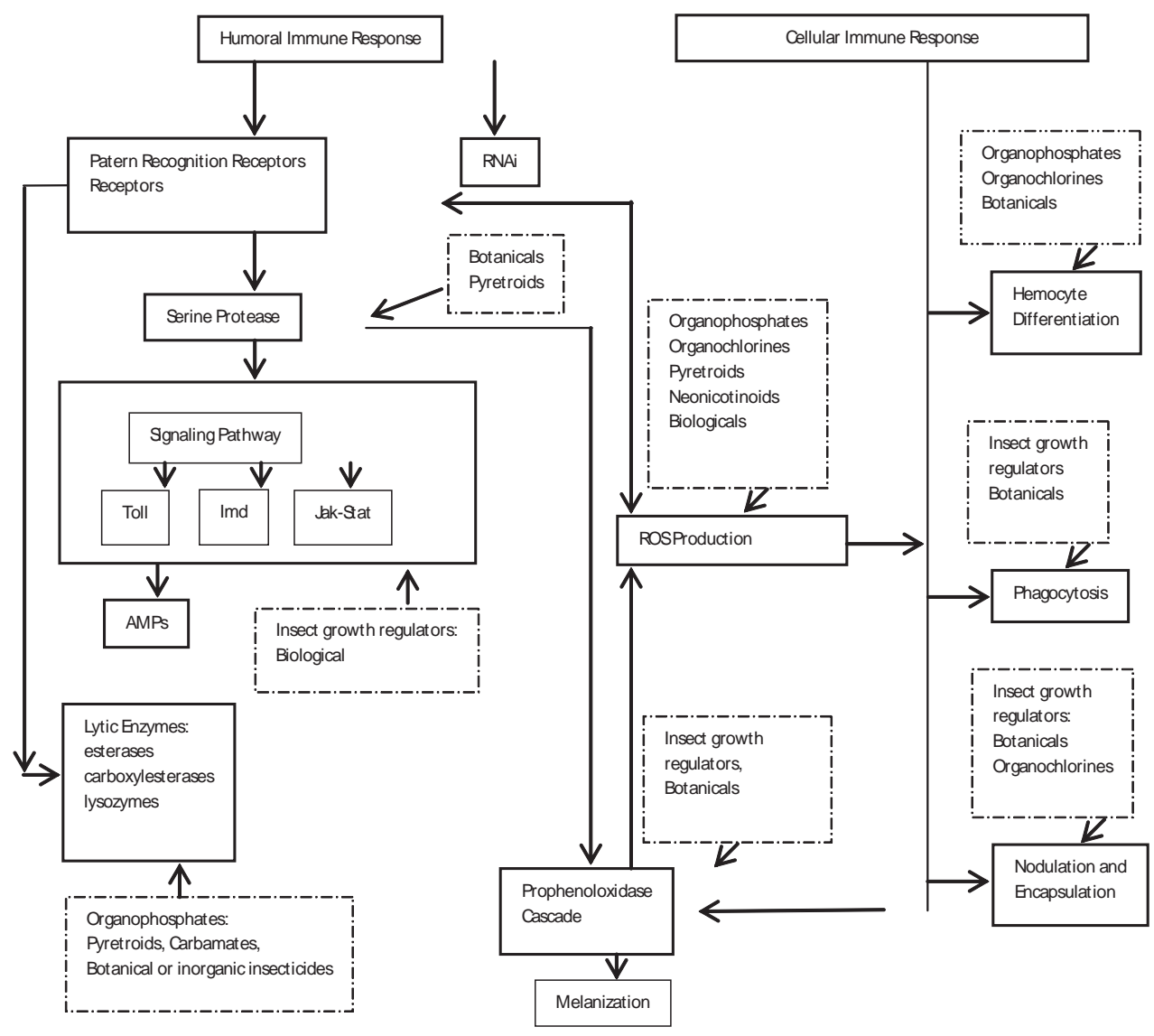

Figure 2. The effect of insecticides on insect immunity. Solid boxes and arrows represent a schematic of the insect immune systém. Dashed boxes and arrows identify where pesticides have been documented to affect particular immune responses [33]. 


\begin{tabular}{ll}
\hline Insecticide class & Insecticide mode of activity \\
\hline Organochlorides & - neurotoxin, disrupt the nervous system \\
\hline Organophosphates & - neurotoxin, interfere with the enzymes acetylcholinesterase and other cholinesterases, \\
& disrupting nerve impulses, killing or disabling the insect \\
& - have an accumulative toxic effect to wildlife, so multiple exposures to the chemicals \\
& amplifies the toxicity \\
& - kill insects by inhibiting the enzyme cholinesterase, which is essential in the functioning of \\
& the nervous system \\
& - have similar toxic mechanisms to organophosphates, but have a much shorter duration of \\
& action and are thus somewhat less toxic \\
- are rapidly detoxified and eliminated from animal tissues & - toxicity is thought to arise from a mechanism somewhat similar to that for the \\
& organophosphates. \\
& - are nonpersistent sodium channel modulators, and are much less acutely toxic than \\
& organophosphates and carbamates. \\
\hline Pyrethroids & broad spectrum systemic insecticides \\
& are nicotinic acetylcholine receptor agonists \\
- have a rapid action (minutes-hours). \\
- treated insects exhibit leg tremors, rapid wing motion, stylet withdrawal (aphids), \\
disoriented movement, paralysis and death \\
\hline Neonicotinoids
\end{tabular}

Table 2. Chemical insecticides with effect on insect immunity

\section{Detoxifying enzymes}

Pesticide resistance in arthropods has been shown to evolve by two main mechanisms at the molecular level either (1) the increased production of metabolic enzymes (esterases, glutathione S-transferases and cytochrome P450 monooxygenases), which can break down or bind to the pesticide, or (2) structural changes (mutations) in the pesticide target protein, which render it less sensitive to the toxic effects of the pesticide [41]. The increased production of the metabolic enzymes is usually mediated via upregulation through mutations in trans and/or cis-acting regulatory loci or through amplification of the structural gene encoding the enzyme [42,43-47]. An alternative way of resistance to pesticides in some cases results from changes in the enzyme coding sequence, which confer an enhanced ability to metabolise the pesticide [48]. Enhanced production of esterases through gene amplification or upregulation has been implicated in resistance to organophosphates, carbamates and pyrethroids in a range of arthropod [42,49]. This can involve slow degradation of insecticide, which exhibit broadspectrum resistance or metabolism of a limited range of insecticides containing a common ester bond [50]. Monooxygenases are mainly involved in the metabolism of pyrethroids and to a lesser extent, detoxification of organophosphates and carbamates [51]. Glutathione S-transferases (GSTs) on the other hand play a role in detoxification of a large range of xenobiotics 
such as to the organochlorine insecticide DDT. They also provide protection against oxidative stress and hormone biosynthesis [52]. The increased production of GSTs has been documented as a mechanism of resistance to organochlorines and pyrethroids and is most commonly mediated through upregulation [42]. The role of glutathione $S$-transferases in resistance to pyrethroids has been attributed to detoxification of lipid peroxidation products induced by pyrethroids rather than to direct metabolism of pyrethroid molecules [53]. P450s play a role in the metabolic resistence of arthropod to a range of different insecticide classes including the pyrethroids, organochlorines, neonicotinoids, organohosphates, carbamates and insect growth regulators [42].

Although acetylcholinesterase (AChE) is a specific target enzyme for organophosphate and carbamate poisoning (specific protein binding), other pesticides or their metabolites can inhibit AChE activity by unspecific protein binding (e.g., interaction with serine groups outside of the catalytic subunit). The latter interaction would also result in a reduction of AChE activity.

\subsection{Glutathione-S-transferases}

Glutathione-S-transferases (EC 2.5.1.18) constitute a family of enzymes that participe in 1) detoxification of xenobiotics, 2) protection from oxidative damage, and 3) intracellular transport of hormones, endogenous metabolites and exogenous chemicals. It is involved in insecticide resistance. Glutathione S-transferases (GSTs) are present in almost all animals and in most of them in multiple isoenzymic forms, constituting a significant intracellular mechanism of detoxification. The enzymes catalyse the conjugation of a large variety of compounds bearing an electrophilic site, with reduced glutathione (GSH) [54]. In insects, they represent a very interesting detoxification mechanism due to their involvement in tolerance to insecticides [55-58]. GSTs of different sub-families and classes are universally present in all forms of life, from invertebrates to vertebrates, plants and microorganisms. They have been identified and characterized in such diverse species as Haliotis discus discus [59], Hyphantria cunea [60], Anopheles gambiae [61], Xenopus laevis [62], and white leghorn chicks [63]. In addition, a number of GSTs have been purified and biochemically characterized [64-67]. Though plenty of studies have demonstrated the xenobiotic detoxification activity of GSTs, studies on immunomodulatory properties of GST members are scarce.

Increased levels of GSTs have been associated with resistence to a wide variety of insecticides, maily organophosphates, organochlorides and cyclodienes [68]. Other insecticide classes, such as pyrethroids and carbamates, are probably not detoxified by GSTs [69]. Induction of GST activity has been reported in many insects following treatment with insecticides [70,71]. The activity of insect GSTs has been found to be present in the midgut [72], fat body [73], hemolymph cells and other but more precise sites of GSTs need to be determined. The multiple isoenzymic forms of GST are distinguished by differences in structure and catalytic properties. The expression of isoenzymes depends on many internal and external factors. Age-dependent alteration of GST activities has been demonstrated in both vertebrates and invertebrates [74-76]. Alteration of GST expression induced by various substances in insets has also been reported (e.g.,food quality and administration of certain insecticides) [77-80]. Significant alterations in the isoenzymic profile, leading to the suggestion that the multiple GST isoen- 
zymes present in insects are regulated independently, have also been reported as a result of stress, caused by a variety of factors $[78,81]$. The role of other enzymatic systems (such as esterases and monooxygenases) is emphasized by many investigators as even more important than GSTs in insecticide metabolism by insects [82].

Kim at all. [83] show the expression profiles of GSTs of the bumblebee Bombus ignitus in response to oxidative stress. The sigma-class GST from B. ignitus (BiGSTS) was identified. Comparative analysis indicates that the predicted amino acid sequence of BiGSTS shares a high identity with the sigma-class GSTs of hymenopteran insects such as Apis mellifera. Tissue distribution analyses showed the presence of BiGSTS in all tissues examined, including the fat body, midgut, muscle and epidermis. Under uniform conditions of $\mathrm{H}_{2} \mathrm{O}_{2}$ overload, the expression profile of GSTs and other antioxidant enzyme genes. These findings indicate that GSTs and other antioxidant enzyme genes in B. ignitus are differentially expressed in response to oxidative stress.

In line with the mammalian GST classification, insect GSTs have been classified into six classes: delta, epsilon, omega, theta, sigma, and zeta [84-86]. Due to the important role of GSTs, most studies of GSTs in insects have focused on their role in detoxifying exogenous compounds, in particular insecticides and plant allelochemicals [87-92]. In addition, insect GSTs have been studied for their role in mediating oxidative stress responses. Drosophila melanogaster sigmaclass GST has been reported to play an important part in the detoxification of lipid peroxidation products, suggesting a protective role against oxidative stress [93]. In the mosquito Anopheles gambiae, the expression of epsilon GSTs increased in response to oxidative stress [94]. In the previous studies were investigated the antioxidant enzymes such as superoxide dismutase [95], and phospholipid-hydroperoxide glutathione peroxidase [96], and two [97] from the bumblebee Bombus ignitus. Furthermore, were have previously identified a delta-class GST (BiGSTD) from B. ignitus [98]

\subsection{Esterases}

The esterase family of enzymes hydrolyse ester bonds, which are present in a wide range of insecticides; therefore, these enzymes may be involved in resistance to the main chemicals employed in control programs. Acetylcholinesterase (AChE) is a specific target enzyme for organophosphate and carbamate poisoning (specific protein binding), other pesticides or their metabolites can inhibit AChE activity by unspecific protein binding (e.g., interaction with serine groups outside of the catalytic subunit). The latter interaction would also result in a reduction of AChE activity. AChE has been shown in aphid Myzus persiace [99], mosquitoes, Culex quinquefasciatus and C. pipiens [100] blowfly. In insects, the esterase enzyme patterns have shown high rates of intraspecific and interspecific variations [101]. Acetylcholinesterase enzyme a key enzyme in insect central nervous system, terminates nerve impulses by catalyzing the hydrolysis of the neurotransmitter acetylcholine. Resistance associated with modification ofAChE makes it less sensitive to inhibition by organophosphates and carbamate insecticides.

Bombus hypocrita is one of the dominant bumblebees in China, and is widely used as one of the most crucial pollinators in greenhouse due to easy mass-rearing, strong population and 
effective pollinating performance [102]. However, it is often threatened by organophosphate and carbamate insecticides which are widely used in China, as these insecticides can inhibit the acetylcholinesterase activity in insects. The effect of six common organophosphate and carbamate insecticides on the AChE activity of B. hypokrita was evaluated. The inhibition of six insecticides to AChE from B. hypocrita showed a dosage effect. The inhibitory effects of six insecticides to AChE from high to low are in the following order: isoprocarb > chlorpyrifos > triazophos $>$ bassa $>$ propoxur $>$ profenofos, and B. hypocrita is more sensitive to isoprocarb than to the other five insecticides.

\subsection{Cytochrome P450 monooxygenases}

Cytochrome P450 monooxygenases (P450s) are enzymes important in insects both for the detoxification of xenobiotics, such as pesticides and phytochemicals, and the biosynthesis of endogenous compounds, such as hormones and pheromones. The monooxygenases of insect have several functional roles, including growth, development, feeding and protection against xenobiotics, including resistance to pesticides and tolerance to plant toxins [103].

Monooxygenases are involved in the synthesis and degradation of insect hormones and pheromones. They catalyse many types of reactions including oxygenations, dehalogenations, dealkylations, deaminations, dehydrogenations and isomerations [104]. The enzyme reactions are based on activation of molecular oxygen within sertion of one of its atoms into the substrate and reduction of the other to form water [105]. The genome of every insect species may carry a hundred or so different P450 genes, all evolved from a common ancestral gene. The P450 family is thus one of the oldest and largest gene superfamilies. They do many things: P450 enzymes are found in the biosynthetic pathways of ecdysteroids and juvenile hormones, which are at the center stage of insect growth, development, and reproduction. P450 enzymes metabolize insecticides, resulting either in bioactivation or, more often, in detoxification, the latter process being enhanced in many strains with metabolic resistance to insecticides. Furthermore, P450 metabolism of certain plant chemicals is often the key to the adaptation of insect herbivores to their host plants. P450 enzymes play important roles in the synthesis or degradation of odorants, pheromones, or defensive chemicals. Insect P450 genes are expressed in many tissues; not surprisingly, the digestive tract and fat body are a rich source of P450-dependent metabolism of model substrates. Developmental regulation of P450 gene expression is well documented by biochemical means [106]. It is well established that many cases of metabolic resistance to insecticides are the result of elevated levels of P450 [92]. In vivo suppression or decrease in resistance by application of P450 inhibitors such as the synergist piperonyl butoxide is often used as a diagnostic for P450 involvement. In vitro demonstration of increased P450-dependent metabolism of the insecticide is done more infrequently. Because of the multiplicity of $\mathrm{P} 450$ genes, correlations between resistance and activity of P450 enzymes measured by model substrates, though indicative, are seldom demonstrative. The cytochrome P450-dependent monooxygenases are an extremely important metabolic system involved in the metabolism of xenobiotics and endogenous compounds. The number of P450s in a given insect species currently ranges from 48 in Apis mellifera to 
164 in Aedes aegypti. There are never increasing number of studies that indicate P450s have a much broader role in insects. It is postulated that metabolism of xenobiotics might be the role for only a minority of the P450s in a given insect species. P450-mediated metabolism can result in detoxification of insecticides such as pyrethroids, or can be involved in both the bioactivation and detoxification of insecticides such as organophosphates.

Cytochrome P450 is a hemoprotein which acts as the terminal oxidase in monooxygenase systems. In eukaryotes, most P450s are found in the endoplasmic reticulum or mitochondria. Monooxygenases can oxidize widely diverse substrates and are capable of catalyzing a large array of reactions [107]. This is because each species contains numerous P450s and because of the broad substrate specificity of some isoforms. Insect monooxygenases can be detected in a wide range of tissues. Highest monooxygenase activities are usually associated with the midgut, fat bodies and Malpighian tubules [108], but again the expression of individual P450s can vary between these tissues [95]. In general, total P450 levels are undetectable in eggs, rise and fall in each larval instar, are undetectable in pupae and are expressed at high levels in adults [106]. The patterns of expression of individual P450s can vary within and/or between life stages [107-110].

\section{Conclusion}

Bumblebees are of crucial importance for the pollination of wild flowers and economical important crops in modern agri/horticulture. These pollinators as Bombus terrestris, Bombus impatiens and Bombus ignitus are also commercially reared for the pollination of agricultural and horticultural crops. Foraging worker bees are playing a key role as they are responsible for the amount of food brought to the colony. Therefore hazards of sublethal concentrations of pesticides on them are important. This lack of assessment, therefore, poses a serious problem and standardized laboratory tests for bumblebees are necessary to evaluate the impact of sublethal effects on their foraging behavior.

Over the last three decades, bumble bee populations have experienced global population declines due to environmental factors such as pathogens, pesticide exposure and habitat fragmentation. Given the importance of bumble bees as pollinators of crops and wild flowers, steps must be taken to prevent further declines.

\section{Acknowledgements}

Authors thank the research programme of the Institute of Organic Chemistry and Biochemistry RVO: 61388963 the Czech Science Foundation (grant No. 203/09/1446) and Technology Agency of the Czech Republic (grant No. TA01020969) 


\title{
Author details
}

\author{
Marie Zarevúcka*
}

Address all correspondence to: zarevucka@uochb.cas.cz

Institute of Organic Chemistry and Biochemistry, AS CR, Flemingovo nám, Prague, Czech Republic

\section{References}

[1] Park B.S., Lee S.E. Proteomics in insecticide toxicology. Molecular Cellular Toxicology 2007:3(1) 11-18.

[2] Scott J.G., Wen Z. Cytochromes P450 of insects: the tip of the iceberg. Pest Management Science 2001:57(10) 958-967.

[3] Scott J.G., Insecticide resistance in insect. In Pimentel D.(ed.) Handbook of pest management in Agriculture, Vol.2, CRC Press, Boca Raton, FL, USA, 1991, p 663.

[4] Veerle M., Guy S. Side-Effects of Pesticides on the Pollinator Bombus: An Overview, Pesticides in the Modern World - Pests Control and Pesticides Exposure and Toxicity Assessment,M. Stoytcheva (Ed.), 2011 ISBN: 978-953-307-457-3, InTech, Available from: http://www.intechopen.com/books/pesticides-in-the-modern-world-pests-control-and-pesticides-exposure-andtoxicity-assessment/side-effects-of pesticides-onthe-pollinator-bombus-an-overview.

[5] Blacquière T., Smagghe G., van Gestel C.A., Mommaerts V. Neonicotinoids in bees: a review on concentrations, side-effects and risk assessment. Ecotoxicology. 2012:21(4) 973-92.

[6] Tasei J.N., Ripault G., Rivault E. Hazards of imidacloprid seed coating to Bombus terrestris (Hymenoptera: Apidae) when applied to sunflower. Journal of Economic Entomology 2001:94(3) 623-7.

[7] Cresswell J.E., Page C.J., Uygun M.B., Holmbergh M., Li Y., Wheeler J.G., Laycock I., Pook C.J., de Ibarra N.H., Smirnoff N., Tyler C.R. Differential sensitivity of honey bees and bumble bees to a dietary insecticide (imidacloprid). Zoology 2012:115(6) 365-371.

[8] Whitehorn P.R., O'Connor S., Wackers F.L., Goulson D. Neonicotinoid pesticide reduces bumble bee colony growth and queen production. Science. 2012:336(6079) 351-352. 
[9] Gels J.A., Held D.W., Potter D.A. Hazards of insecticides to the bumble bees Bombus impatiens (Hymenoptera: Apidae) foraging on flowering white clover in turf. Journal of Economic Entomology 2002: 95(4) 722-8.

[10] Scott-Dupree C.D., Conroy L., Harris C.R. Impact of currently used or potentially useful insecticides for canola agroecosystems on Bombus impatiens (Hymenoptera: Apidae), Megachile rotundata (Hymentoptera: Megachilidae), and Osmia lignaria (Hymenoptera: Megachilidae). Journal of Economical Entomology 2009: 102(1) 177-82.

[11] Fanigliulo A., Filì V., Pacella R., Comes S., Crescenzi A. Teppeki, selective insecticide about Bombus terrestris. Communications in Agricultural and Applied Biological Sciences 2009:74(2) 407-10.

[12] Thompson H.M., Hunt L.V. 1999. Extrapolating from honeybees to bumblebees in pesticide risk assessment. Ecotoxicology 1999:8(3) 147-166.

[13] Davis A.R., Shuel R.W. Distribution of carbofuran and dimethoate in flowers and their secretion in nectar as related to nectary vascular supply. Canadian Journal of Botany 1988:66(7) 1248-1255.

[14] Thompson H.M. 2001. Assessing the exposure and toxicity of pesticides to bumblebees (Bombus sp.). Apidologie 2001: 32(4) 305-321.

[15] Free J.B., Ferguson A.W. Foraging of bees on oil-seed rape (Brassica napus L.) in relation to the flowering of the crop and pest control. Journal of Agricultural Sciences 1980: 94(1)151-154.

[16] Ernst W.R., Pearce P.A., Pollock T.L. 1989. Environmental effects of Fenitrothion use in forestry. Conservation and Protection, Environment Canada, Atlantic Region, Canada.

[17] Morandin L.A., Winston M.L., Franklin M.T., Abbott V.A. Lethal and sub-lethal effects of spinosad on bumble bees (Bombus impatiens Cresson). Pest Management Science 2005: 61(7) 619-626.

[18] Franklin M.T., Winston M.L., Morandin L.A. Effects of clothianidin on Bombus impatiens (Hymenoptera: Apidae) colony health and foraging ability. Ecotoxicology 2004: 97(2) 369-373.

[19] Sechser B., Freuler J. The impact of thiomethoxam on bumble bee broods (Bombus terrestris L.) following drip application in covered tomato crops. Journal of Pest Science 2003:76(3)74-77.

[20] Morandin L.A., Winston M.L., Franklin M.T., Abbott V.A. Lethal and sub-lethal effects of spinosad on bumble bees (Bombus impatiens Cresson). Pest Management Science 2005:61(7) 619-626. 
[21] Mommaerts V., Sterk G., Smagghe G. Hazards and uptake of chitin synthesis inhibitors in bumblebees Bombus terrestris. Pest Management Science 2006:62(8) 752-758.

[22] Isayama S., Saito S., Kuroda K., Umeda K., Kasamatsu K. Pyridalyl, a novel insecticide: potency and insecticidal selectivity. Archives of Insect Biochemistry and Physiology 2005:58(4) 226-33.

[23] Gradish A.E., Scott-Dupree C.D., Shipp L., Harris C.R., Ferguson G. Effect of reduced risk pesticides for use in greenhouse vegetable production on Bombus impatiens (Hymenoptera: Apidae). Pest Management Science 2010:66(2) 142-6.

[24] Besard L., Mommaerts V., Abdu-Alla G., Smagghe G. Lethal and sublethal side-effect assessment supports a more benign profile of spinetoram compared with spinosad in the bumblebee Bombus terrestris. Pest Managemnet Science 2011:67(5) 541-7.

[25] Iwasa T., Motoyama N., Ambrose J.T., Roe M.R. Mechanism for the differential toxicity of neonicotinoid insecticides in the honey bee, Apis mellifera. Crop Protection 2004:23(5) 371-378.

[26] Laurino D., Porporato M., Patetta A., Manino A. Toxicity of neonicotinoid insecticides to honey bees laboratory tests. Bull Insectol 2011:64(1) 107-113.

[27] Mommaerts V., Reynders S., Boulet J. Besard L., Sterk G., Smagghe G. Risk assessment for side-effects of neonicotinoids against bumblebees with and without impairing foraging behaviour. Ecotoxicology 2010:19(1) 207-215.

[28] Suchail S., De Sousa G., Rahmani R., Belzunces L.P. In vivo distribution and metabolisation of C-14-imidacloprid in different compartments of Apis mellifera L. Pest Management Science 2004:60(11) 1056-1062.

[29] Suchail S., Debrauwer L., Belzunces L.P. Metabolism of imidacloprid in Apis mellifera. Pest Management Science 2004:60(3) 291-296.

[30] Brunet J.L., Badiou A., Belzunces L.P. In vivo metabolic fate of [C-14]-acetamiprid in six biological compartments of the honeybee, Apis mellifera L. Pest Management Science 2005:61(8) 742-748.

[31] Jones A.K., Raymond-Delpech V., Thany S.H., Gauthier M., Sattelle D.B. The nicotinic acetylcholine receptor gene family of the honey bee, Apis mellifera. Genome Research 2006:16(11) 1422-1430.

[32] Scott-Dupree C.D., Conroy L., Harris C.R. Impact of currently used or potentially useful insecticides for canola agroecosystems on Bombus impatiens (Hymenoptera: Apidae), Megachile rotundata (Hymenoptera: Megachilidae), and Osmia lignaria (Hymenoptera: Megachilidae). Journal of Economic Entomology 2009:102(1) 177-182.

[33] James R.R., Xu J. Mechanisms by which pesticides affect insect immunity. Journal of Invertebrate Pathology 2012:109(2) 175-182. 
[34] Aronstein K.A., Murray K.D. Chalkbrood disease in honey bees. Journal of Invertebrate Pathology 2010:103(Suppl 1) S20-S29.

[35] Glinski Z. Immuno-suppressive and immuno-toxic action of contaminated honey bee products on consumers. Medycina Weterynaryjna 2000: 56(10) 634-638.

[36] Glinski Z. Kauko L. Problems of immunosuppression and immunotoxicolgy in respect to the honeybee protection against microbial and parasitic nvaders. Apiacta 2000:35(2) 65-76.

[37] Hetru C., Hoffmann D., Bulet P., 1998. Antimicrobial peptides from insects. In: Brey, P.T., Hultmark,D. (Eds.), Molecular Mechanisms of Immune Responses inInsects. Chapman and Hall, NY, pp. 40-66.

[38] Ragan E.J., An C., Jiang H., Kanost M.R. 2009. Roles of haemolymph proteins in antimicrobial defenses of Manduca sexta. In: Rolff, J., Reynolds, S.E. (Eds.), Insect Infection and Immunity, Evolution, Ecology and Mechanisms. Oxford University Press, Oxford, pp. 34-48.

[39] Casteels P., Ampe C., Jacobs F., Vaeck M., Tempst P. Apidaecins, antibacterial peptides from honeybees. EMBO Journal 1989:8(8) 2387-2391.

[40] Li W.F., Ma G.X., Zhou X.X. 2006. Apidaecin-type peptides, Biodiversity, structurefunction relationships and mode of action. Peptides 2006:27(9) 2350-2359.

[41] Bass C., Field L.M. Gene amplification and insecticide resistance Pest Management Science 2011: 67(8) 886-890.

[42] Li X.C., Schuler M.A., Berenbaum M.R. Molecular mechanisms of metabolic resistance to synthetic and natural xenobiotics. Annual Reviews Entomology 2007:52 231253.

[43] Hemingway J., Karunaratne S.H. Mosquito carboxylesterases: a review of the molecular biology and biochemistry of a major insecticide resistance mechanism. Medical and Veterinary Entomology 1998:12(1) 1-12.

[44] Huang H.S., Hu N.T., Yao Y.E., Wu C.Y., Chiang S.W., Sun, C.N. Molecular cloning and heterologous expression of a glutathione-Stransferase involved in insecticide resistance from the diamondback moth Plutella xylostella. Insect Biochemistry and Molecular Biology 1998:28(9) 651- 658.

[45] Daborn P.J., Yen J.L., Bogwitz M.R., Le Goff G., Feil E., Jeffers S., Tijet N., Perry T., Heckel D., Batterham P., Feyereisen R., Wilson T.G., ffrench-Constant, R.H. A single P450 allele associated with insecticide resistance in Drosophila. Science 2002:297(5590) 2253-2256.

[46] Nikou D., Ranson H., Hemingway J. An adult-specific CYP6 P450 gene is overexpressed in a pyrethroid-resistant strain of the malaria vector, Anopheles gambiae. Gene 2003:318(1) 91-102. 
[47] Festucci-Buselli R.A., Carvalho-Dias A.S., de Oliveira-Andrade M., Caixeta- Nunes C., Li, H.M., Stuart J.J., Muir, W., Scharf M.E., Pittendrigh B.R. Expression of Cyp6g1 and Cyp12d1 in DDT resistant and susceptible strains of Drosophila melanogaster. Insect Molecular Biology 2005:14(1) 69-77.

[48] Claudianos C., Russell R.J., Oakeshott J.G. The same amino acid substitution in orthologous esterases confers organophosphate resistance on the house fly and a blowfly. Insect Biochemistry and Molecular Biology 1999:29(8) 675-686.

[49] Hemingway J., Ranson H. Insecticide resistance in insect vectors of human disease. Annual Review of Entomology 2000:45 371-391.

[50] Hemingway J. The molecular basis of two contrasting metabolic mechanisms of insecticide resistance. Insect Biochemistry and Molecular Biology 2000:30(11)1009-1015.

[51] Feyereisen R. Insect P450 enzymes. Annual review of Entomology 1999:44(1) 507-533.

[52] Enayati A.A., Ranson H., Hemingway J. Insect glutathione transferases and insecticide resistance. Insect Molecular Biology 2005:14(1) 3-8.

[53] Vontas J., Small G.J., Hemingway J. Glutathione S-transferases as antioxidant defence agents confer pyrethroid resistance in Nilaparvata lugens. Biochemical Journal 2001:357(1) 65-72.

[54] Mannervik B., lin P., Guthenberg C., Jensson H., Tahir M.K., Warholm M., Jornvall H.. Identification of three classes of cytosolic glutathione transferases common to several mammalian species: correlation between structural data and enzymatic properties. Proceedings of the National Academy of Sciences USA 1985:82(21) 7202-7206.

[55] Motoyama N., Dauterman W.C., Glutathione S-transferases: their role in the metabolism of organophosphorus insecticides. Review of Biochemical Toxicology 1980:2(1) $49-69$.

[56] Clark A.G., Dick G.L., Martindale S.M., Smith J.N. Glutathione S-transferases from the New Zealand grass grub, Costelytra zealandica: their isolation and characterization and the effect on their activity of endogenous factors. Insect Biochemistry 1985:15(1) 35-44.

[57] Fournier D., Bride J.M., Poirie M., Berge J.-B., Plapp Jr. F. Insect glutathione S-transferases: biochemical characteristics of the major forms from houseflies susceptible and resistant to insecticides. Journal of Biological Chemistry 1992:267(3) 1840-1845.

[58] Kostaropoulos I., Papadopoulos A.I., Metaxakis A., Boukouvala E., PapadopoulouMourkidou E., 2001. Glutathione S-transferase in the defense against pyrethroids in insect. Insect Biochem Mol Biol 2001:31(4-5) 313-319.

[59] Wan Q., Whang I., Lee J. Molecular cloning and characterization of three sigma glutathione S-transferases from disk abalone (Haliotis discus discus). Comparative Biochemistry and Physiology B 2008:151(3) 257-267. 
[60] Yamamoto K., Fujii H., Aso Y., Banno Y., Koga K. Expression and characterization of a sigma-class glutathione S-transferase of the fall webworm, Hyphantria cunea. Biosci Biotechnol Biochem 2007:71(9) 553-560.

[61] Ranson H., Rossiter L., Ortelli F., Jensen B., Wang X., Roth C.W., Collins F.H., Hemingway J., Identification of a novel class of insect glutathione Stransferases involved in resistance to DDT in the malaria vector Anopheles gambiae. Biochemical Journal 2001:359(Pt 2) 295-304.

[62] Carletti E., De Luca A., Urbani A., Sacchetta P., Di Ilio C. Sigma-class glutathione transferase from Xenopus laevis: molecular cloning, expression, and site-directed mutagenesis. Archives of Biochemistry and Biophysics 2003:419(2) 214-221.

[63] Hsieh C.H., Liu L.F., Tsai S.P., Tam M.F. Characterization and cloning of avianhepatic glutathione S-transferases. Biochemistry 1999:343(Pt 1) 87-93.

[64] Tomarev S.I., Zinovieva R.D., Guo K., Piatigorsky J. Squid glutathione Stransferase.Relationships with other glutathione S-transferases and S-crystallins of cephalopods. Journal of Biological Chemistry 1993:268(6) 4534-4542.

[65] Fitzpatrick P.J., Krag T.O., Hojrup P., Sheehan D. Characterization of a glutathione Stransferase and a related glutathione-binding protein from gill of the blue mussel, Mytilus edulis. Biochemical Journal 1995:305(Pt 1) 145-150.

[66] Hoarau P., Garello G., Gnassia-Barelli M., Romeo M., Girard J.P. Purification and partial characterization of seven glutathione S-transferase isoforms from the clam Ruditapes decussatus. European Journal of Biochemistry 2002:269(17) 4359-4366.

[67] Yang H.L., Zeng Q.Y., Nie L.J., Zhu S.G., Zhou X.W. Purification and characterization of a novel glutathione S-transferase from Atactodea striata. Biochemical and Biophysical Research Communications 2003:307(3) 626-631.

[68] Fournier D., Bride J.M., Poirie M., Berge J.B., Plapp F.W.Jr. Insect glutathione Stransferase: biochemical characteristics of the major forms from houseflies susceptible and resistant to insecticides. Journal of Biological Chemistry 1992:267(3) 1840-1845.

[69] Grant D.F., Matsumura F. Glutathione S-transferases 1 and 2 in susceptible and insecticide resistant Aedes aegypti. Pesticide Biochemistry and Physiology 1989:33(2) 132-143.

[70] lagadic L., Cuany A., Berge J.B. Echaubard M., Purification and partial characterisation of glutathione S-transferases from insecticide-resistant and lindane-induced susceptible Spodoptera littoralis (Boisd) larvae. Insect Biochemistry and Molecular Biology 1993:23(4) 467-474.

[71] Punzo F., Detoxification enzymes and the effects of temperature on the toxicity of pyrethrpoids to the fall armyworm, Spodoptera frugiperda (Lepidoptera: Noctudae). Comparative Biochemistry Physiology C 1993:105(1) 155-158. 
[72] Tate L.G., Nakat S.S., Hodgson E. Comparison of detoxification activity in midgut and fat body during fifth instar development of the tobacco hornworm, Manduca sexta. Comparative Biochemistry and Physiology C 1982:72(1) 75-81.

[73] Chien C., Dauterman W.C. Studies on glutathione S-transferase in Helicoverpa. Insect Biochemistry 1991:21(8) 857-864.

[74] Gregus Z., Varga F., Schmelas A. Age-development and inducibility of hepatic glutathione S-transferase activities in mice, rats, rabbits and guinea-pigs. Comparative Biochemistry and Physiology 1985:C 80(1) 85-90.

[75] Hazelton G.A., Lang C.A. Glutathione S-transferase activities in the yellow-fever mosquito [Aedes aegypti (Louisville)] during growth and ageing. Biochemical Journal 1983:210(1) 281-287.

[76] Kostaropoulos I., Mantzari A.E., Papadopoulos A.I. Alterations of some glutathione S-transferase characteristics during the development of Tenebrio molitor (Insecta: Coleoptera). Insect Biochemistry and Molecular Biology 1996:26(8-9) 963-969.

[77] Hayaoka T., Gauterman W.C. Induction of glutathione S transferase by phenobarbital and pesticides in various housefly strains and its effect on toxicity. Pesticide Biochemistry and Physiology 1982:17(2) 113-119.

[78] Papadopoulos A.I., Stamkou E.I., Kostaropoulos I., Papadopoulou-Mourkidou E. Effect of organophosphate and pyrethroid insecticides on the expression of GSTs from Tenebrio molitor larvae. Pesticide Biochemistry and Physiology 1999:63(1) 26-33.

[79] Papadopoulos A.I., Boukouvala E., Kakaliouras G., Kostaropoulos I., PapadopoulouMourkidou E. Effect of organophosphate and pyrethroid insecticides on the expression of GSTs from Tenebrio molitor pupae. Pesticide Biochemistry and Physiology 2000:68(1) 26-33.

[80] Kostaropoulos I., Papadopoulos A.I., Metaxakis A., Boukouvala E., PapadopoulouMourkidou E., Glutathione S-transferase in the defense against pyrethroids in insect. Insect Biochemistry and Molecular Biology 2001:31(3-4) 313-319.

[81] Papadopoulos A.I., Polemitouc E., Laifi P., Yiangou A., Tananaki T. Glutathione Stransferase in the developmental stages of the insect Apis mellifera macedonica. Comparative Biochemistry and Physiology C 2004:C139(1) 87-92.

[82] Karunaratne S.H.P.P., Hemingway J. Different insecticides select multiple carboxyesterase isoenzymes and different resistance levels from a single population of Culex quinquefascians. Pestic Biochem Physiol 1996:54(1) 4-11.

[83] Kim BY, Hui WL, Lee KS, Wan H, Yoon HJ, Gui ZZ, Chen S, Jin BR. Molecular cloning and oxidative stress response of a sigma-class glutathione S-transferase of the bumblebee Bombus ignitus. Comparative Biochemistry and Physiology B 2011:158(1) 83-9. 
[84] Chelvanayagam G., Parker M.W., Board P.G. Fly fishing for GSTs: a unified nomenclature for mammalian and insect glutathione transferases. Chemico-Biological Interactions 2001:133(1-3) 256-260.

[85] Ranson H., Claudianos C., Ortelli F., Abgrall C., Hemingway J., Sharkhova M.V., Unger M.F., Collins F.H., Feyereisen R. Evolution of supergene families associated with insecticide resistance. Science 2002:298 179-181.

[86] Claudianos C., Ranson H., Johnson R.M., Biswas S., Schuler M.A., Berenbaum M.R., Feyereisen R., Oakeshott J.G. A deficit of detoxification enzymes: pesticide sensitivity and environmental response in the honeybee. Insect Molecular Biology 2006:15(6) 615-636.

[87] Huang H.S., Hu N.T., Yao Y.E., Wu C.Y., Chiang S.W., Sun C.N. Molecular cloning and heterologous expression of a glutathione $\mathrm{S}$-transferase involved in insecticide resistance from the diamondback moth, Plutella xylostella. Insect Biochemistry and Molecular Biology 1998:28(9) 651-658.

[88] Ranson H., Rossiter L., Ortelli F., Jensen B.,Wang X., Roth C.W., Collins F.H., Hemingway J., Identification of a novel class of insect glutathione S-transferases involved in resistance to DDT in themalaria vector Anopheles gambiae. Biochemical Journal 2001:359(2) 295-304.

[89] Ortelli F., Rossiter L.C., Vontas J., Ranson H., Hemingway J. Heterologous expression of four glutathione transferase genes genetically linked to a majorinsecticide-resistance locus from the malaria vector Anopheles gambiae. Biochemical Journal 2003:373(3) 957-963.

[90] Enayati A.A., Ranson H., Hemingway J. Insect glutathione transferases andinsecticide resistance. Insect Molecular Biology 2005:14(1) 3-8.

[91] Francis F., Vanhaelen N., Haubruge E. Glutathione S-transferases in theadaptation to plant secondary metabolites in the Myzus persicae aphid. Archives of Insect Biochemistry and Physiology 2005:58(3) 166-174.

[92] Lumjuan N., McCarroll L., Prapanthadara L., Hemingway J., Ranson H. Elevated activity of an epsilon class glutathione transferase confers DDT resistance in the dengue vector, Aedes aegypti. Insect Biochemistry and Molecular Biology 2005:35(8) 861-871.

[93] Singh S.P., Coronella J.A., Benes H., Cochrane B.J., Zimniak P. Catalytic function of Drosophila melanogaster glutathione S-transferase DmGSTS1-1 (GST-2) in conjugation of lipid peroxidation end products. European Journal of Biochemistry 2001:268(10) 2912-2923.

[94] Ding Y., Hawkes N., Meredith J., Eggleston P., Hemingway J., Ranson, H. Characterization of the promoters of epsilon glutathione transferases in themosquito Anopheles 
gambiae and their response to oxidative stress. Biochemical Journal 2005:387(3) 879888.

[95] Choi Y.S., Lee K.S., Yoon H.J., Kim I., Sohn H.D., Jin B.R. Bombus ignitus Cu, Zn superoxide dismutase (SOD1): cDNA cloning, gene structure, and up-regulation in response to paraquat, temperature stress, or lipopolysaccharide stimulation. Comparative Biochemistry and Physiology B 2006:144(2) 365-371.

[96] Hu Z.G., Lee K.S., Choo Y.M., Yoon H.J., Kim I., Wei Y.D., Gui Z.Z., Zhang G.Z., Sohn H.D., Jin B.R. Molecular characterization of a phospholipid-hydroxide glutathione peroxidase from the bumblebee Bombus ignitus. Comparative Biochemistry and Physiology B 2010:155(1) 54-61.

[97] Hu Z., Lee K.S., Choo Y.M., Yoon H.J., Lee S.M., Wei Y.D., Lee J.H., Sohn H.D., Jin B.R., Molecular cloning and characterization of 1-Cys and 2-Cys peroxiredoxins from the bumblebee Bombus ignitus. Comparative Biochemistry Physiology B 2010:155(3) $272-280$.

[98] Park, J.H., Yoon, H.J., Gui, Z.Z., Jin, B.R., Sohn, H.D., 2009. Molecular cloning of a delta class glutathione S-transferase gene from Bombus ignitus. International Journal of Industrial Entomology 2009: 18(1) 31-35.

[99] Field L.M., Devonshire A.L.: Evidence that the E4 and FE4 esterase genes responsible for insecticide resistance in the aphid Myzus persicae (Sulzer) are part of a gene family. Biochemical Journal 1998:330(1) 169-173.

[100] Guillemaud T., Makate N., Raymond M., Hirst B., Callaghan A. Esterase gene amplification in Culex pipiens. Insect Molecular Biology 1997:6(4) 319-327.

[101] Nascimento A.P., Bicudo H.E.M.D. Esterase patterns and phylogenetic relationships of Drosophila species in the saltans subgroup (saltans group). Genetica 2002:114(3) 41- 51 .

[102] Liao X.Li Luo ShuDong, Wu Xiang, Wu Jie Optimization of conditions for assaying activity of acetylcholinesterase in Bombus hypocrita (Hymenoptera: Apidae) and its sensitivity to six common, insecticides. Acta Entomologica Sinica 2011:54(12) 1361-1367.

[103] Scott J.G., Liu N., Wen Z.M. Insect cytochromes P450 diversity, insecticide resistance and tolerance to plant toxins. Comp Biochem Physiol C 1998:121(1-3) 147-155.

[104] Nebert D.W., Gonzalez F.J. P450 genes: structure, evolution and regulation. Annual Review of Biochemistry 1987:56 945-993.

[105] Guengerich P.F. Reactions and significance of cytochrome P-450enzymes. Journal of Biological Chemistry 1991:266(17) 10019-10022. 
[106] Agosin M. 1985. Role of microsomal oxidations in insecticide degradation. In Kerkur G.A. (ed.) Comprehensive insect physiology, biochemistry and pharmacology. Vol. 12, pp 647-712 Pergamon, New York.

[107] Mansuy D. The great diversity of reactiins catalysed by cytochrome P450. Comparative Biochemical Physiology C 1998:121(1-3) 5-14.

[108] Hodgson E. The significance of cytochrome P450 in insects. Insect Biochemistry 1983:13(3) 237-246.

[109] Cohen M.B., Feyereisen R. A cluster of cytochrome P450 genes of the CYP6 family in the house fly. DNA and Cell Biology 1995:14(1) 73-82.

[110] Scott J.G., Sridhar P., Liu N. Adult specific expression and induction of cytochrome P450trp in house flies. Archives Insect Biochemistry and Physiology 1996:31(3) 313-323. 